\title{
KAJIAN KERENTANAN MASYARAKAT TERHADAP PERUBAHAN IKLIM BERBASIS DAERAH ALIRAN SUNGAI (STUDI KASUS SUB DAS GARANG HULU)
}

\author{
Muchtar Efendi*, Henna Rya Sunoko**, Widada Sulistya*** \\ * Program Magister Ilmu Lingkungan Undip, Jl. Imam Bardjo No. 5 Semarang, arriva_fendy@yahoo.com \\ ** Program Doktor Ilmu Lingkungan Undip, Jl. Imam Bardjo No.5 Semarang, hennarsunoko@gmail.com \\ *** Badan Meteorologi Klimatologi dan Geofisika, Jl. Angkasa I No.2 Kemayoran, Jakarta Pusat, w_sulistya@yahoo.co.id
}

\begin{abstract}
ABSTRAK
Dampak terhadap pemanasan global adalah terjadinya perubahan iklim yang berpengaruh terhadap kondisi ekosistem Daerah Aliran Sungai (DAS). Kondisi ini menyebabkan penurunan tingkat kesejahteraan masyarakat dan meningkatkan tingkat kerentanan masyarakat. Penelitian ini bertujuan melakukan analisis tingkat kerentanan masyarakat terhadap perubahan iklim di Sub DAS Garang Hulu. Penelitian ini merupakan penelitian deskriptif-eksploratif dengan menggunakan pendekatan metode kombinasi kualititatif dan kuantitatif (mixed method). Data sekunder dikumpulkan melalui kegiatan studi literatur dan desk study. Data primer berupa persepsi masyarakat dengan wawancara mendalam dengan metode purposive sampling. Penilaian kerentanan masyarakat terhadap perubahan iklim menggunakan fungsi dari tiga komponen, yaitu paparan, kepekaan, dan kemampuan adaptasi. Hasil analisis kerentanan masyarakat ditampilkan dalam bentuk peta-peta dengan bantuan Sistem Informasi Geografi (SIG). Hasil kajian menunjukkan bahwa tingkat kerentanan masyarakat terhadap perubahan iklim didominasi dalam kategori rendah sampai dengan sedang

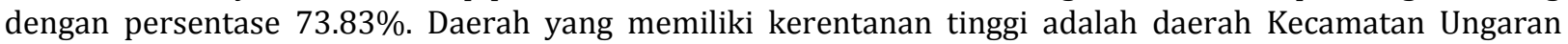
Timur dan kelurahan Sukorejo di Kota Semarang.
\end{abstract}

Kata Kunci : DAS, Kerentanan, Paparan, Kepekaan, Kemampuan Adaptasi

\begin{abstract}
The impact of global warming is climate change affecting the condition of Watershed Ecosystem. This condition causes the decreasing in the level of social welfare and the increasing level of vulnerability of living community. This study was aimed to analyze the level of vulnerability of living communities due to climate change in Garang Hulu sub-watersheds. This research was a descriptive-explorative approach by using a combination of qualititative and quantitative methods (mixed method). Secondary data were collected through the study of literature and desk study. Primary data were taken in the form of public perception along with indepth interviews. Respondents were chosen through purposive sampling method. Assessment of the social vulnerability to climate change was using a function of three components, namely the exposure, sensitivity, and adaptability. The results of the vulnerability analysis were presented in the form of maps using the GIS. The study results showed that the level of vulnerability of communities to climate change was dominated by low category to moderate with the percentage of $73.83 \%$. Areas that had a high vulnerability were East Ungaran local district and Sukorejo village in Semarang.
\end{abstract}

Key Words : watershed, vulnerability, exposure, sensitivity, adaptability.

\section{Pendahuluan}

Pemanasan global sudah bukan lagi merupakan masalah masa depan, tetapi sudah menjadi masalah yang sedang kita hadapi sekarang. Hasil penelusuran terhadap database bencana alam intenasional (International Disaster Database) menunjukkan bahwa banyak bencana alam yang masuk ke dalam kategori bencana global ialah sebanyak 345 bencana (Boer dan Perdinan, 2008). Temuan ini sejalan dengan hasil kajian Panel Antar Pemerintah tentang Perubahan Iklim (IPCC, 2007) bahwa pemanasan global akan meningkatkan frekuensi dan intensitas kejadian iklim ekstrim.

Penelitian tentang pengaruh pemanasan global terhadap perubahan 
musim di pulau Jawa sudah dilakukan oleh Naylor dkk. (2007). Hasil penelitian mereka menunjukkan bahwa dalam 40 tahun mendatang, terjadinya pemanasan global akan menyebabkan awal musim hujan di Jawa Tengah akan mengalami kemunduran sedangkan akhir musim hujan akan lebih cepat yang berarti lama musim hujan akan semakin pendek. Di lain pihak curah hujan musim hujan akan cenderung meningkat sedangkan curah hujan musim kemarau cenderung menurun. Hal ini berimplikasi pada semakin meningkatnya risiko kekeringan pada musim kemarau dan risiko banjir atau bahaya longsor pada musim hujan. WWF (2007) menyatakan perubahan distribusi curah hujan tersebut menyebabkan berbagai potensi bencana alam yang dipicu oleh curah hujan menjadi semakin tinggi, seperti : banjir, longsor, peluapan sungai, dan penyebaran vektor penyakit. Sedangkan pada kondisi curah hujan yang mengecil dapat terjadi potensi bencana seperti : kekeringan, gagal panen, kekurangan air bersih, dan berbagai permasalahan sosial yang mungkin timbul.

Dampak dari kejadian iklim ekstrim diperkirakan akan semakin parah apabila kerusakan lingkungan khususnya kerusakan tutupan hutan di wilayah tangkapan hujan dalam Daerah Aliran Sungai (DAS) semakin besar. Salah satu DAS di Provinsi Jawa Tengah yang mengalami kerusakan dan rentan terhadap perubahan iklim adalah DAS Garang (Kemenhut, 2009). Berdasarkan Keputusan Menteri Kehutanan Nomor SK.328 tahun 2009 DAS Garang Merupakan DAS Prioritas dalam Rencana Pembangunan Jangka Menengah (RPJM) RPJM Tahun 2010-2014. Hasil analisis proyeksi perubahan iklim di DAS Garang berdasarkan skenario emisi A2 dan B1 menunjukkan bahwa secara umum terjadinya penurunan peluang curah hujan melebihi batas kritis yang terkait dengan banjir khususnya di bagian tengah dari kota tersebut. Sedangkan pada musim kemarau terjadi peningkatan curah hujan yang berdampak pada berkurangnya kemungkinan terjadinya kekeringan di masa depan (Acccrn, 2010).

DAS Garang menyediakan sumber daya alam yang banyak memberikan banyak manfaat bagi penduduk di sekitarnya, antara lain sebagai sumber daya pertanian, sumber air bersih, sumber perikanan air tawar maupun pemanfaatan air lainnya. DAS Garang merupakan salah satu DAS yang kritis di Jawa Tengah. Berbagai aktivitas masyarakat di sepanjang DAS Garang berpengaruh pada kondisi kualitas dan kuantitas DAS Garang. Selain itu, isu perubahan iklim telah memperparah kondisi DAS Garang. Peningkatan suhu serta curah hujan berpengaruh pada kondisi hidrologi DAS Garang.

$$
\text { Degradasi DAS Garang }
$$

menyebabkan ekosistem tidak dapat optimal menyediakan fungsi dan jasa yang sangat penting bagi kehidupan manusia. Kondisi ini menyebabkan penurunan tingkat kesejahteraan masyarakat dan meningkatkan tingkat kerentanan masyarakat. Kerentanan masyarakat merupakan kondisi masyarakat yang tidak dapat menyesuaikan dengan perubahan ekosistem yang disebabkan oleh suatu ancaman tertentu (Fussel, 2007). Kerentanan merupakan fungsi dari tiga komponen, yaitu exposure (paparan), sensitivity (kepekaan), dan adaptive capacity (kemampuan adaptasi) (IPCC, 2001).

Dampak utama terhadap perubahan iklim adalah tingkat kesejahteraan masyarakat baik daerah hulu, tengah maupun hilir. Banyak penelitian tentang tingkat kerentanan terhadap perubahan iklim yang dilakukan di wilayah pesisir pantai. Miladan (2009) menyatakan 
bahwa wilayah pesisir kota Semarang dalam ketegori tingkat kerentanan rendah dan sedang terhadap perubahan iklim. Rositasari dkk (2011) dengan teknik penginderaan jauh memetakan tingkat kerentanan pesisir di Cirebon. Penelitian tingkat kerentanan terhadap masyarakat di daerah hulu sangat jarang dilakukan, padahal keberadaan daerah hulu menjadi faktor penentu terhadap keberlanjutan fungsi DAS di sektor tengah dan hilir. Bagian hulu DAS Garang merupakan daerah tangkapan hujan untuk sungai yang mengalir ke Kota Semarang. Kerusakan wilayah Daerah Aliran Sungai (DAS) Garang Hulu ini akan berdampak di Kota Semarang. Oleh karena itu, penelitian ini menganalisis tingkat kerentanan masyarakat terhadap perubahan iklim di DAS Garang bagian hulu.

\section{Material dan Metode}

Penelitian ini merupakan penelitian deskriptif-eksploratif. Perubahan iklim tidak dibahas secara detil dan hanya digunakan untuk menunjukkan bahwa telah terjadi perubahan iklim berdasarkan kajian pola dan tren sebaran curah hujan yang diperoleh dari data sekunder di wilayah kajian. Penelitian dilakukan di DAS Garang Hulu yang berada pada 3 (tiga) kabupaten yaitu Kabupaten Semarang, Kabupaten Kendal dan Kota Semarang dengan 7 (tujuh) kecamatan yaitu Kecamatan Ungaran Barat, Ungaran Timur, Limbangan, Bandungan, Bergas, Banyumanik dan Gunung Pati. Jumlah desa yang terdapat dalam lokasi penelitian sebanyak 27 desa/kelurahan.

Pengambilan lokasi ditentukan dengan metode purposive sampling. Pertama lokasi dipilih secara strata berdasarkan pembagian wilayah administrasi kecamatan yang berada pada DAS Garang hulu. Kemudian dari basis kecamatan dipilih lokasi/desa yang dianggap mewakili kondisi pada setiap kecamatan di DAS Garang hulu. Lokasi yang dipilih dalam penelitian ini adalah: a). Kecamatan Limbangan (Desa Ngesrep Balong); b). Kecamatan Ungaran Barat (Desa Lerep dan Gogik); c). Kecamatan Bergas (Desa Munding); d). Kecamatan Ungaran Timur (Desa Sidomulyo dan Wujil); e). Kecamatan Bandungan (Desa Sidomukti); f). Kecamatan Banyumanik (Desa Srondol Kulon) dan g). Kecamatan Gunungpati (Desa Patemon).

Data yang digunakan adalah data primer dan sekunder. Data sekunder dikumpulkan melalui kegiatan studi literatur dan desk study. Data primer berupa persepsi masyarakat dengan wawancara mendalam dengan metode purposive sampling. Responden dipilih dari 9 (sembilan) desa yang terpilih yang merupakan sampel dari wilayah studi yaitu DAS Garang hulu untuk mendapatkan informasi tentang perubahan iklim, perilaku konservasi masyarakat. Syarat dalam pemilihan responden adalah : a) penduduk yang sudah lama tinggal di daerah tersebut, minimal 20 tahun; b) dewasa; c) bersedia dan memiliki kemampuan untuk menjelaskan tentang tema atau topik yang dibicarakan; d). Tokoh masyarakat atau perangkat desa/kelurahan; e). Petani pemilik lahan.

Penilaian kerentanan masyarakat terhadap perubahan iklim menggunakan fungsi dari tiga komponen, yaitu paparan, kepekaan, dan kemampuan adaptasi (IPCC 2001; Fonner 2006 dalam Swandayani 2010 ). Analisis kriteria dan indikator paparan diperoleh dari beberapa referensi, terutama dari Bappenas (2010) tentang peta jalan perubahan iklim Indonesia, Kementerian Lingkungan hidup, GTZ, WWF (2010) tentang kajian risiko dan adaptasi perubahan iklim pulau Lombok Provinsi Nusa Tenggara Barat serta ACCCRN (2010) yang menjelaskan kajian 
kerentanan dan adaptasi terhadap perubahan iklim di kota Semarang. Kriteria dan Indikator yang digunakan dalam penelitian ini dapat dilihat pada Tabel 1.

Hasil analisis kerentanan masyarakat ditampilkan dalam bentuk peta-peta dengan bantuan perangkat lunak ArcView GIS 3.3 dan Arc Gis 9.3. Peta yang dihasilkan adalah peta paparan, kepekaan, kemampuan adaptasi, dan kerentanan. Peta kerentanan masyarakat terhadap perubahan iklim diperoleh dengan operasi overlay atau tumpang tindih antara peta paparan, peta kepekaan masyarakat dan peta kemampuan adaptasi. Penentuan indeks kerentanan dilakukan dengan mengurangi hasil jumlah indeks paparan dan kepekaan dengan indeks kemampuan adaptasi

\section{Hasil dan Pembahasan \\ 3.1. Pemetaan Paparan}

Pemetaan paparan merupakan hasil tumpang tindih (overlay) peta curah hujan, peta penutupan lahan dan peta tingkat kekritisan lahan di wilayah Sub DAS Garang Hulu. Peta Curah dibuat dengan menggunakan data rata-rata curah hujan tahunan pada stasiun yang terdapat di Sub DAS Garang Hulu yang dipetakan dengan menggunakan polygon thiessen. Nilai rata-rata hujan tahunan berkisar $2.200 \mathrm{~mm} / \mathrm{th}-2.650 \mathrm{~mm} / \mathrm{th}$. Peta penutupan lahan dan tingkat kekritisan menggunakan peta yang dikeluarkan oleh Kementerian Kehutanan Tahun 2010. Hasil pemetaan paparan perubahan iklim Sub DAS Garang terlihat pada Gambar 1.

Pada Gambar 1. terlihat bahwa daerah-daerah yang memiliki curah hujan tinggi dengan penutupan lahan pemukiman memiliki tingkat paparan yang tinggi dibandingkan dengan daerahdaerah yang memiliki curah hujan rendah dengan penutupan lahan hutan atau tegalan. Kondisi ini diakibatkan bahwa curah hujan yang tinggi pada daerah pemukiman akan menjadi aliran permukaan (run off) yang akan berdampak terhadap ketersediaan air tanah. Daerah-daerah yang memiliki penutupan lahan hutan atau tegalan memiliki kemampuan melakukan infiltrasi terhadap air hujan yang jatuh ke tanah sehingga dapat menyimpan air dalam tanah.

Tabel 1. Kriteria dan Indikator Kerentanan Masyarakat terhadap perubahan Iklim

\begin{tabular}{|c|c|c|c|}
\hline Elemen & Kriteria & Indikator & Keterangan \\
\hline $\begin{array}{l}\text { Paparan } \\
\text { (Exposure) }\end{array}$ & $\begin{array}{l}\text { Perubahan kondisi } \\
\text { di Sub DAS Garang } \\
\text { Hulu }\end{array}$ & $\begin{array}{l}\text { 1. Curah Hujan } \\
\text { 2. Pola Penggunaan Lahan } \\
\text { 3. Tingkat Kekritisan Lahan }\end{array}$ & \\
\hline Kepekaan & Permintaan Air & 1. Kepadatan Penduduk & \\
\hline \multirow{6}{*}{$\begin{array}{l}\text { Kemampuan } \\
\text { Adaptasi } \\
\text { (Adaptive } \\
\text { capacity) }\end{array}$} & $\begin{array}{l}\text { Semakin Tinggi } \\
\text { Keteranguntan } \\
\text { pada Lahan }\end{array}$ & $\begin{array}{l}\text { 2. Akses Terhadap Air Bersih } \\
\text { Persentase masyarakat yang } \\
\text { tergantung pada lahan pertanian }\end{array}$ & $\begin{array}{l}\text { Asumsi : Sektor Pertanian sangat } \\
\text { tergantung pada perubahan iklim }\end{array}$ \\
\hline & Kualitas SDM & 1. Indeks Pendidikan & \\
\hline & Sosial Ekonomi & $\begin{array}{l}\text { 2. Perilaku Konservasi } \\
\text { 1. Tingkat Kesejahteraan Masyarakat }\end{array}$ & \\
\hline & Masyarakat & 2. Konflik antar Masyarakat & \\
\hline & Fasilitas Kesehatan & $\begin{array}{l}\text { 3. Dukungan Pemerintah Terhadap } \\
\text { Masyarakat } \\
\text { Tingkat Fasilitas kesehatan yang ada }\end{array}$ & \\
\hline & $\begin{array}{l}\text { Adanya daerah } \\
\text { resapan air }\end{array}$ & $\begin{array}{l}\text { Persentase lahan selain areal terbuka } \\
\text { dan terbangun }\end{array}$ & $\begin{array}{l}\text { Asumsi : Selain areal terbuka dan } \\
\text { terbangun mempunyai potensi } \\
\text { untuk melakukan infiltrasi air ke } \\
\text { tanah, sedangkan kemampuan } \\
\text { infiltrasi diabaikan }\end{array}$ \\
\hline
\end{tabular}

Sumber : Bappenas (2010), KNLH (2010) dan Swandayani (2010), (Dirjen RRL, 1998) 


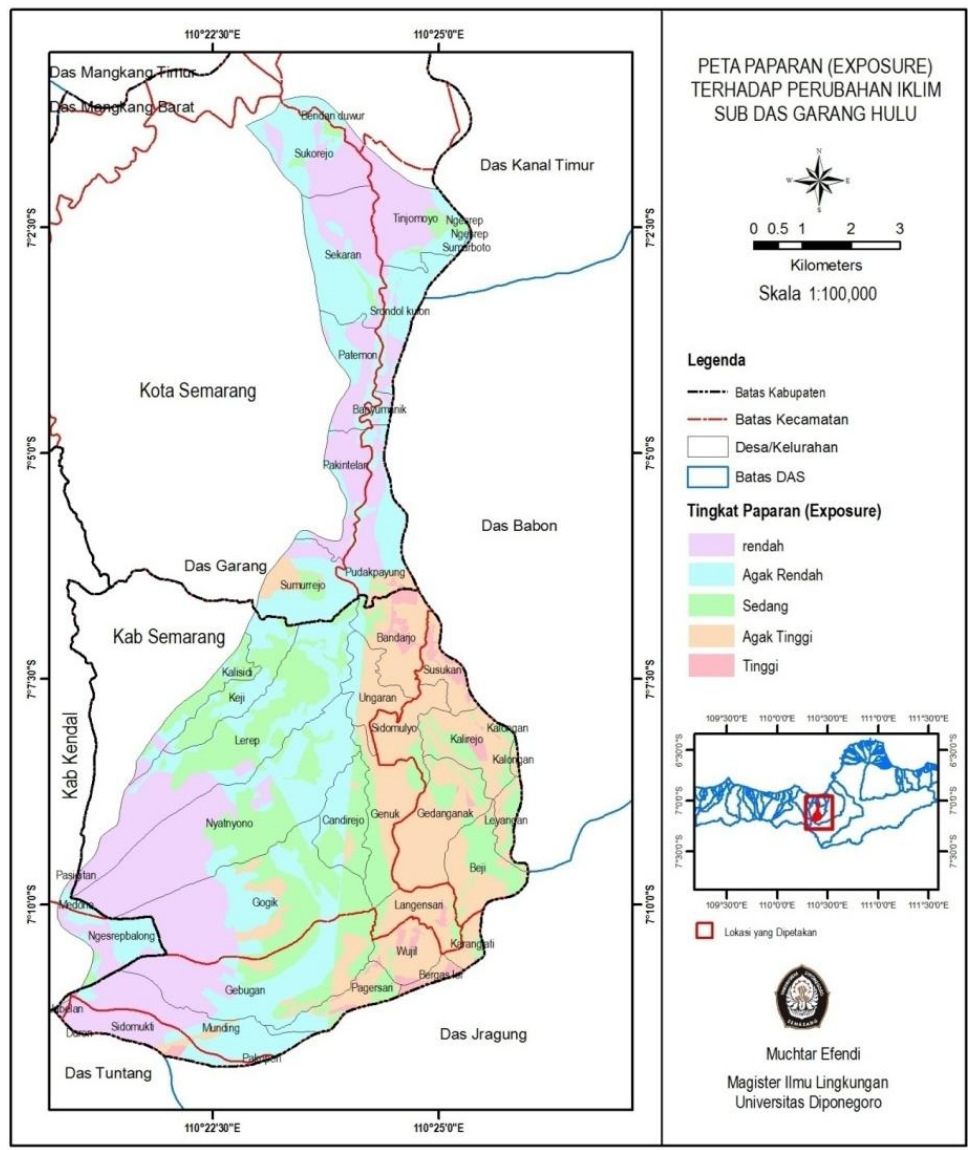

Gambar 1. Peta Paparan Perubahan Iklim Sub DAS Garang

Pawitan dkk (2003) menyatakan bahwa ketersediaan air dipengaruhi oleh perubahan penggunaan lahan yang berdampak terhadap fluktuasi aliran air dengan gejala banjir dan kekeringan yang ekstrim. Daya dukung DAS baik di permukaan (tanaman, sawah, rawa, danau/waduk dan sungai) maupun bawah permukaan (lapisan tanah dan airbumi) akan merupakan faktor dominan yang menentukan kerentanan dan daya dukung sistem sumber daya air wilayah terhadap perubahan iklim.

\section{Pawitan (2011) menyatakan} respon hidrologi wilayah dipengaruhi oleh perubahan iklim global yang dicirikan oleh permukaan bumi, curah hujan wilayah, limpasan permukaan evapotranpirasi, simpanan air bumi dan sebagainya. Pengaruh tersebut menentukan ketersediaan air wilayah untuk berbagai kebutuhan dan ikut menentukan nilai ekologi, sosial dan ekonomi sumber daya air yang ada. Rahardjo (2009) menyatakan bahwa perubahan penggunaan lahan yang tidak sesuai dengan kaidah konservasi tanah dan air cenderung meningkatkan koefisien aliran permukaan yang akan berpengaruh terhadap debit puncak. Kondisi ini akan berdampak terhadap ketersediaan air tanah dimana fungsi daerah resapan menjadi penting dalam adaptasi perubahan iklim.

Dampak paparan terhadap perubahan iklim dapat mengancam keberlanjutan jasa ekosistem Daerah Aliran Sungai. Jasa-jasa ekosistem terancam oleh berbagai tekanan manusia selain perubahan iklim, seperti perubahan tata guna lahan, fragmentasi bentang alam, degradasi habitat, pengambilan sumberdaya yang berlebihan, polusi, penumpukan nitrogen 
dan spesies-spesies bersifat invasi (Locatelli dkk, 2009). Perubahan iklim akan memperburuk tekanan-tekanan tersebut dalam dekade mendatang. Tren
Ungaran Barat, Gunung Pati serta Boja dan Limbangan yang kegiatan alih fungsi lahan menjadi pemukiman relatif belum banyak memiliki indeks paparan yang

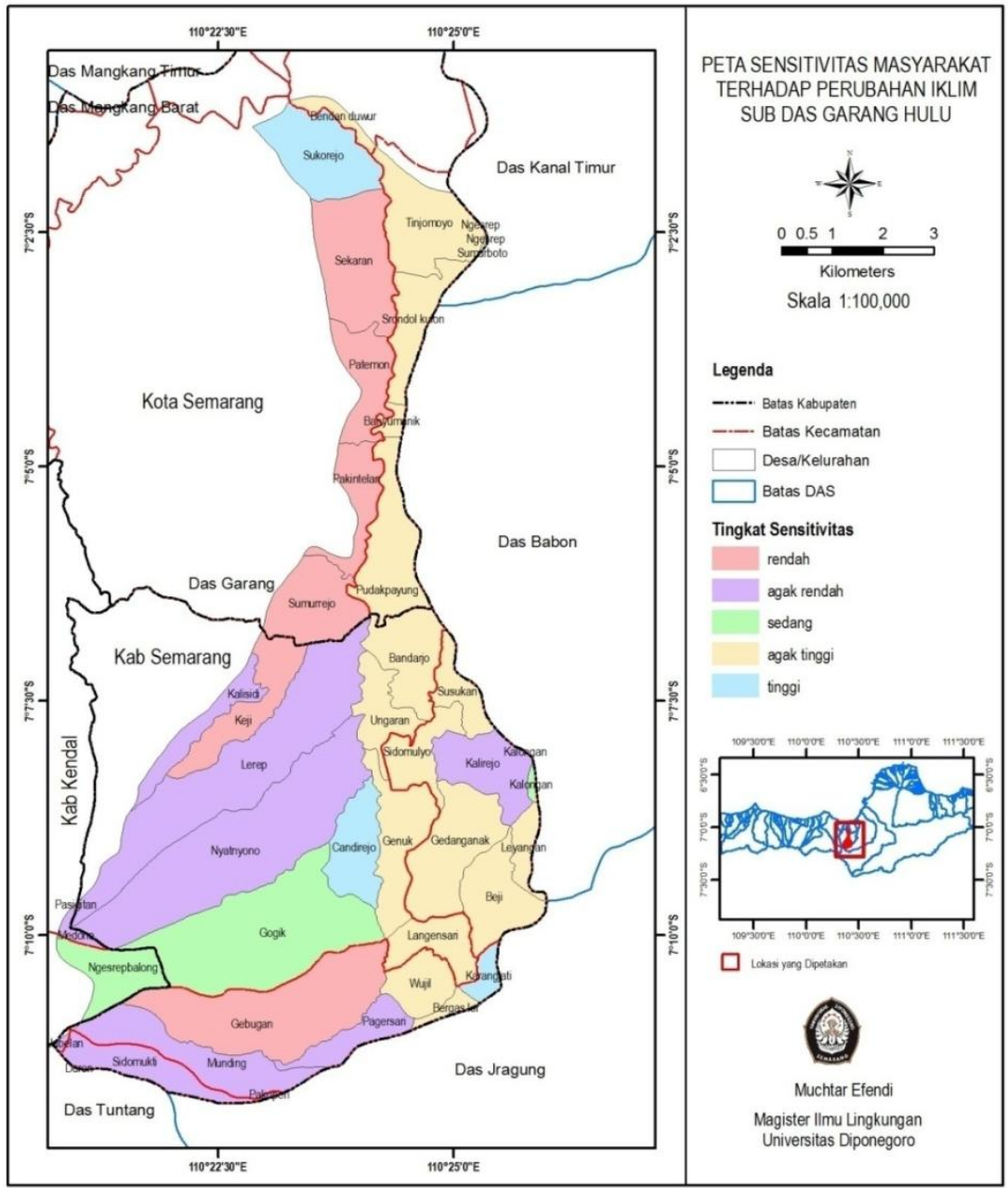

Gambar 2. Peta Kepekaan Masyarakat Terhadap Perubahan Iklim

perubahan iklim akan mempengaruhi spesies dan ekosistem dan mengakibatkan menurunnya jasa-jasa ekosistem (Leemans dan Eickhout, 2004). Hilangnya jasa-jasa ekosistem akan mengurangi kesejahteraan manusia di semua tingkatan.

Pada Gambar 1. terlihat bahwa daerah kecamatan Ungaran Timur dan kecamatan Banyumanik dengan curah hujan yang tinggi dengan penutupan lahan yang sebagian besar pemukiman memiliki indeks paparan dalam kategori agak tinggi dan tinggi. Sedangkan kecamatan lainnya yaitu Bandungan, rendah-sedang.

\subsection{Pemetaan Kepekaan}

Tabel 2. Kelas Kepekaan Masyarakat Terhadap Perubahan Iklim

\begin{tabular}{lccr}
\hline \multicolumn{1}{c}{ Kelas } & Indeks & Luas (Ha) & $\begin{array}{r}\text { Persentase } \\
(\%)\end{array}$ \\
\hline Rendah & $<0.84$ & $1,800.83$ & 21.51 \\
agak rendah & $0.84-1.11$ & $2,630.24$ & 31.42 \\
Sedang & $1.12-1.39$ & 752.96 & 8.99 \\
agak tinggi & $1.40-1.66$ & $2,650.66$ & 31.66 \\
Tinggi & $>1.66$ & 536.75 & 6.41 \\
\hline
\end{tabular}

Sumber : Data sekunder diolah (2012)

Pemetaan kepekaan masyarakat terhadap perubahan iklim dipengaruhi oleh tingkat kepadatan penduduk, akses 
terhadap air bersih dan ketergantungan masyarakat terhadap lahan. Berdasarkan analisis pembobotan dengan AHP diperoleh bahwa tingkat kepadatan penduduk memiliki bobot yang lebih tinggi dibandingkan lainnya. Hasil pemetaan masyarakat dapat dilihat dalam Gambar 2, sedangkan persentase luas untuk masing-masing kelas kepekaan masyarakat disajikan dalam Tabel 1.

Berdasarkan Tabel 2 terlihat bahwa kepekaan masyarakat dalam kategori rendah sampai agak rendah dengan persentase jumlah keduanya 52,93\%. Dari Gambar 2. terlihat bahwa pendorong utama kebutuhan air, sementara itu ketersediaannya dipengaruhi oleh peningkatan evaporasi (penguapan) akibat peningkatan temperatur permukaan bumi. Daerahdaerah dengan kepadatan penduduk tinggi akan memiliki tingkat kepekaan lebih tinggi dibandingkan daerah-daerah yang lainnya. Daerah kecamatan Ungaran Timur, Banyumanik memiliki tingkat kepekaan agak tinggi sedangkan kelurahan Candirejo dan Sukorejo memiliki tingkat kepekaan yang tinggi.

Daerah kecamatan Ungaran Timur, Banyumanik serta Kelurahan Candirejo dan Sukorejo selain memiliki

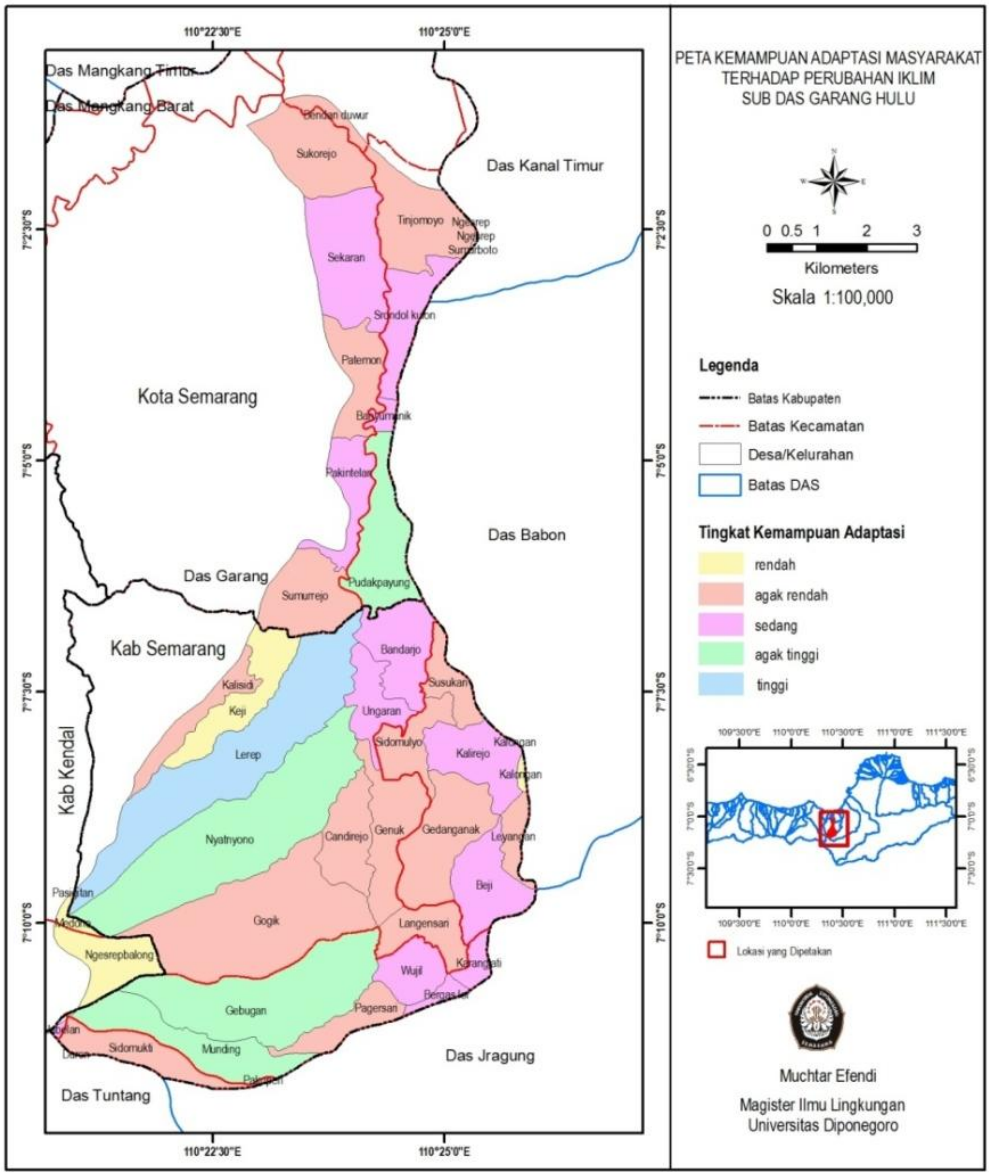

Gambar 3. Peta Kemampuan Adaptasi Masyarakat Terhadap Perubahan Iklim

tingkat kepadatan penduduk sangat berperan dalam menentukan tingkat sensitivitas masyarakat. Vorosmarty (2000) menunjukkan peningkatan jumlah penduduk dan ekonomi menjadi tingkat kepadatan penduduk yang tinggi juga akses terhadap ketersediaan air lebih sulit terutama yang tidak belangganan dengan PAM. Hal tersebut yang menyebabkan daerah-daerah 
dimaksud memiliki tingkat sensitivitas yang agak tinggi sampai tinggi. Sebaliknya daerah Ungaran Barat yang dekat sumber air walaupun tidak berlangganan dengan PAM memiliki tingkat ketersediaan air yang cukup tinggi dengan tingkat kepadatan penduduk yang tidak terlalu padat menjadikan tingkat kepekaan masyarakat terhadap perubahan iklim dalam kategori rendah-sedang.

\subsection{Pemetaan Kemampuan Adaptasi}

Kemampuan adaptasi masyarakat dipengaruhi oleh kualitas Sumber Daya Manusia (SDM), kemampuan ekonomi, fasilitas kesehatan serta faktor fisik. Kualitas SDM dipengaruhi oleh tingkat pendidikan serta perilaku konservasi.
Adanya tingkat pendidikan dan pengetahuan yang tinggi akan meningkatkan kemampuan adaptasi dari masyarakat selain faktor-faktor yang lainnya. Peningkatan kemampuan faktorfaktor tersebut di atas akan berbanding lurus dengan kemampuan adaptasi masyarakat terhadap perubahan iklim. Peta kemampuan adaptasi masyarakat terhadap perubahan iklim tersaji pada Gambar 3. Pada Gambar 3 terlihat bahwa Desa Nyatnyono memiliki kemampuan adaptasi yang tinggi, kemudian kecamatan Banyumanik, kecamatan Bergas dan desa Lerep memiliki kemampuan adaptasi agak tinggi. Selain faktor tingkat pendidikan kemampuan adaptasi juga dipengaruhi oleh

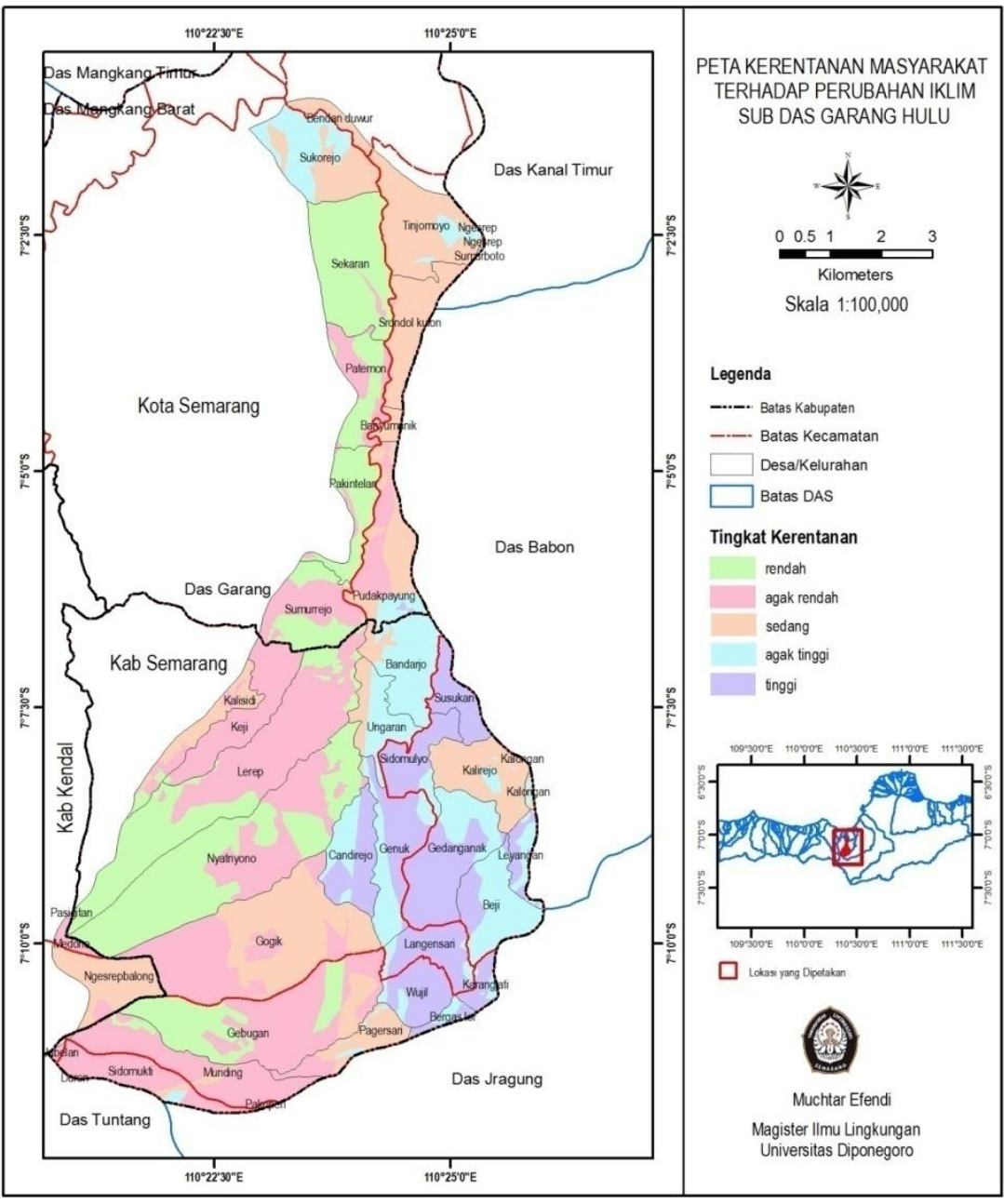

Gambar 4. Peta Kerentanan Masyarakat Terhadap perubahan Iklim 
kesejahteraan masyarakat di wilayah tersebut.

Tabel 3. Kelas Kemampuan Adaptasi Masyarakat Terhadap Perubahan iklim

\begin{tabular}{lccr}
\hline $\begin{array}{c}\text { Kemampuan } \\
\text { Adaptasi }\end{array}$ & Indeks & Luas (Ha) & $\begin{array}{c}\text { Persentase } \\
\text { (\%) }\end{array}$ \\
\hline Rendah & $<0.94$ & 426.81 & 5.10 \\
agak rendah & $0.94-1.09$ & $3,429.57$ & 40.97 \\
Sedang & $1.10-1.23$ & $1,741.93$ & 20.81 \\
agak tinggi & $1.24-1.38$ & $2,023.43$ & 24.17 \\
Tinggi & $>1.38$ & 749.69 & 8.96 \\
\hline
\end{tabular}

Sumber : Data sekunder diolah (2012)

Sebagian besar Sub DAS Garang Hulu memiliki kemampuan adaptasi dalam kategori agak rendah dengan persentase sebesar 40,97. Kondisi tersebut disebabkan faktor rendahnya lahan resapan yang terdapat pada Sub DAS Garang Hulu selain rendahnya dukungan pemerintah terhadap kegiatan adaptasi perubahan iklim. Persentase kelas kemampuan adaptasi masyarakat disajikan dalam Tabel 3.

\subsection{Pemetaan Kerentanan}

Hasil pemetaan kerentanan masyarakat terhadap perubahan iklim tersaji pada Gambar 4. Kerentanan masyarakat berbanding lurus dengan paparan dan kepekaan masyarakat serta berbanding terbalik dengan kemampuan adaptasi. Kelas kerentanan masyarakat di Sub DAS Garang Hulu dalam kategori didominasi rendah sampai sedang dengan persentase mencapai $73,83 \%$ sedangkan yang lainnya dalam kategori agak tinggi sampai tinggi. Kelas kerentanan masyarakat terhadap perubahan iklim di Sub DAS Garang dapat dilihat pada Tabel 4.

Tabel 4. Kelas Kerentanan Masyarakat Terhadap Perubahan Iklim

\begin{tabular}{lccc}
\hline $\begin{array}{c}\text { Kelas } \\
\text { Kerentanan }\end{array}$ & Indeks & luas (ha) & $\begin{array}{c}\text { Persentase } \\
(\%)\end{array}$ \\
\hline Rendah & $<0.46$ & $1,856.97$ & 22.18 \\
agak rendah & $0.46-0.67$ & $2,438.01$ & 29.12 \\
Sedang & $0.68-0.89$ & $1,885.92$ & 22.53 \\
agak tinggi & $0.90-1.10$ & $1,107.21$ & 13.23 \\
Tinggi & $>1.10$ & $1,083.32$ & 12.94 \\
\hline
\end{tabular}

Sumber : Data sekunder diolah (2012)

Berdasarkan gambar 4 terlihat bahwa Kecamatan Ungaran Timur memiliki tingkat kerentanan yang agak tinggi sampai tinggi yang menunjukkan bahwa daerah tersebut sangat rentan terhadap perubahan iklim. Daerah tersebut memiliki kepekaan yang rendah sedangkan kemampuan adaptasinya juga rendah. Kepadatan penduduk dan belum baiknya infrastruktur untuk mendapatkan air bersih serta terjadinya alih fungsi lahan dari tegalan dan hutan menjadi peruntukkan pemukiman dan jalan transportasi menjadikan daerah tersebut rentan apabila terjadi perubahan iklim. Di lain pihak kemampuan adaptasi masyarakat pada daerah tersebut relatif masih rendah yang akan menambah tingkat kerentanan pada masyarakat.

\section{Kesimpulan}

Hasil

kajian kerentanan masyarakat terhadap perubahan iklim menunjukkan hubungan antar elemen kerentanan. Tingkat kerentanan merupakan hubungan positif dari kepekaan masyarakat dan paparan dan hubungan negatif dari kemampuan adaptasi masyarakat. Kriteria kepekaan (sensitivitas) merupakan hal paling penting dibandingkan paparan dan kemampuan adaptasi dalam pemetaan kerentanan masyarakat terhadap perubahan iklim di Sub DAS Garang Hulu. Tingkat kerentanan masyarakat di DAS Garang Hulu didominasi kategori rendah sampai sedang.

\section{Ucapan Terima Kasih}

Pusbindiklatren Bappenas yang telah memberikan dukungan dan beasiswa dalam penulisan artikel jurnal ini. Dr. Henna Rya Sunoko, Apt.,MES dan Dr. Widada Sulistya, DEA sebagai pembimbing utama dan pendamping dalam penyelesaian artikel ini. 


\section{DAFTAR PUSTAKA}

Asian Cities Climate Change Resilence Network (ACCCRN). 2010. Laporan Akhir Kajian Kerentanan dan Adaptasi terhadap perubahan iklim di Semarang.

Badan Perencanaan Pembangunan Nasional (Bappenas). 2010. Indonesia Climate Change Sectoral Roadmap.

Boer, Rizaldi dan Perdinan. 2008. Adaptation to climate variability and climate change: Its socio-economic aspect. Paper presented at the EEPSEA Conference On Climate Change: Impacts, Adaptation, And Policy In South East Asia With A Focus On Economics, Socio-Economics And Institutional Aspects, 13-15 February 2008, Bali, <http://www.eepsea.ccsea.org $>$, diakses tanggal 11 Februari 2012.

IPCC (Intergovernmental Panel on Climate Change). 2001. Climate change 2001. Impacts, adaptation and vulnerability. Contribution of Working Group II to the Third Assessment Report of the Intergovernmental Panel on Climate Change. Cambridge University Press. Cambridge, UK.

IPCC (Intergovernmental Panel on Climate Change). 2007. Climate change 2007. Synthesis report. Contribution of Working Groups I, II and III to the Fourth Assessment Report of the Intergovernmental Panel on Climate Change.

Fussel. H. Martin. 2007. Vulnerability: A Generally Applicable Conceptual Framework for Climate Change Research. Global Environment Change, 17 : 155-167.

Kementerian Kehutanan. 2009. Rencana Strategis Kementerian Kehutanan 2010-2014.

Kementerian Lingkungan Hidup, GTZ, WWF. 2010. Kajian Risiko dan Adaptasi terhadap Perubahan Iklim Pulau Lombok Provinsi Nusa Tenggara Barat.

Leemans, R. dan Eickhout, B. 2004 Another reason for concern: regional and global impacts on ecosystems for different levels of climate change.
Global Environmental Change 14: 219-228.

Locatelli, B., Kanninen, M., Brockhaus, M., Colfer, C.J.P., Murdiyarso, D. dan Santoso, H. 2009 Menghadapi masa depan yang tak pasti: Bagaimana hutan dan manusia beradaptasi terhadap perubahan iklim. Perspektif Kehutanan no. 5. CIFOR, Bogor, Indonesia.

Miladan, Nur. 2009. Kajian Kerentanan Wilayah Pesisir Kota Semarang Terhadap Perubahan Iklim. Tesis Magister Teknik Pembangunan Wilayah dan Kota. Universitas Diponegoro (Tidak Diterbitkan)

Naylor, R.L., Battisti, D.S. Vimont, D.J., Falcon, W.P. and Burke, M.B. 2007. Assessing risks of climate variability and climate change for Indonesian rice agriculture. Proceeding of the National Academic of Science. 114:7752-7757.

Pawitan, H, Boer,R., Kusmaryono,Y dan Baharsjah, J.S. 2003. Perubahan Iklim Global dan Dampaknya Terhadap Masa Depan Sumber Daya Air dan Ketersediaan Air Indonesia. Makalah disajikan dalam Seminar Nasional "Air untuk Masa Depan" dalam rangka Peringatan Hari Air Sedunia 2003, Jakarta, 20 Maret 2003.

Pawitan. 2011. Arti Perubahan Iklim Global dan Pengaruhnya dalam Pengelolaan Daerah Aliran Sungai di Indonesia. Proseeding Ekspose Hasil Penelitian dan Pengembangan Pengelolaan DAS dalam Mitigasi dan Adaptasi Perubahan Iklim di Indonesia. Pusat Penelitian dan Pengembangan Konservasi dan Rehabilitasi. Bogor.

Rahardo,Puguh Dwi. 2009. Perubahan Penggunaan lahan DAS Kreo Terhadap Debit Puncak dengan Aplikasi Penginderaan Jauh. Jurnal Riset Geologi dan Pertambangan. Vol 19 (2) : 69-84.

Rositasari, Rocky., Setiawan, Wahyu.B, Supriadi,Indarto.H, Hasanuddin dan Prayuda, Bayu. 2011. Kajian dan Prediksi Kerentanan Pesisir Terhadap Perubahan Iklim: Studi Kasus di Pesisir Cirebon. Jurnal Ilmu dan 
Teknologi Kelautan Tropis. Vol. 3(1). pp: 52-64.

Swandayani, Tri Hastuti,. 2010. Pemetaan Kerentanan Masyarakat Terhadap Perubahan Iklim dan Adaptasi Berbasis Ekosistem Hutan (Studi Kasus: DAS Ciliwung). Tesis tidak dipublikasikan. Sekolah Pascasarjana IPB. Bogor.
Vorosmarty, C. J., Green, P., Salisbury, J. And Lammers, R.B. 2000. Global Water Resources: Vulnerability from Climate Change and Population Growth. J. Science. 289. 284 - 288

World Wildlife Fund (WWF). 2007. Dampak Perubahan Iklim Terhadap Pengelolaan DAS Citarum. WWF Indonesia. Jakarta 